\title{
Small-Sized Parabolic Trough Collector System for Solar Dehumidification Application: Design, Development, and Potential Assessment
}

\author{
Ghulam Qadar Chaudhary $\mathbb{D}^{1,2}$ Rubeena Kousar, ${ }^{1}$ Muzaffar Ali ${ }^{10},{ }^{1}$ Muhammad Amar, ${ }^{2}$ \\ Khuram Pervez Amber, ${ }^{2}$ Shabaz Khan Lodhi, ${ }^{1}$ Muhammad Rameez ud Din, ${ }^{1}$ \\ and Allah Ditta ${ }^{1,2}$ \\ ${ }^{1}$ University of Engineering and Technology, Taxila, Punjab, Pakistan \\ ${ }^{2}$ Mirpur University of Science and Technology (MUST), Mirpur, 10250 AJK, Pakistan
}

Correspondence should be addressed to Ghulam Qadar Chaudhary; gq.chaudhary@hotmail.com

Received 19 August 2017; Revised 13 November 2017; Accepted 27 November 2017; Published 21 February 2018

Academic Editor: Gabriele Battista

Copyright (c) 2018 Ghulam Qadar Chaudhary et al. This is an open access article distributed under the Creative Commons Attribution License, which permits unrestricted use, distribution, and reproduction in any medium, provided the original work is properly cited.

\begin{abstract}
The current study presents a numerical and real-time performance analysis of a parabolic trough collector (PTC) system designed for solar air-conditioning applications. Initially, a thermodynamic model of PTC is developed using engineering equation solver (EES) having a capacity of around $3 \mathrm{~kW}$. Then, an experimental PTC system setup is established with a concentration ratio of 9.93 using evacuated tube receivers. The experimental study is conducted under the climate of Taxila, Pakistan in accordance with ASHRAE 93-1986 standard. Furthermore, PTC system is integrated with a solid desiccant dehumidifier (SDD) to study the effect of various operating parameters such as direct solar radiation and inlet fluid temperature and its impact on dehumidification share. The experimental maximum temperature gain is around $5.2^{\circ} \mathrm{C}$, with the peak efficiency of $62 \%$ on a sunny day. Similarly, maximum thermal energy gain on sunny and cloudy days is $3.07 \mathrm{~kW}$ and $2.33 \mathrm{~kW}$, respectively. Afterwards, same comprehensive EES model of PTC with some modifications is used for annual transient analysis in TRNSYS for five different climates of Pakistan. Quetta revealed peak solar insolation of $656 \mathrm{~W} / \mathrm{m}^{2}$ and peak thermal energy $1139 \mathrm{MJ}$ with $46 \%$ efficiency. The comparison shows good agreement between simulated and experimental results with root mean square error of around $9 \%$.
\end{abstract}

\section{Introduction}

Global energy consumption trends are increasing progressively over the past few decades, and fossil fuels are leading with $80 \%$ share [1]. Solar energy is one of the best ecofriendly renewable energy resources available in the world. The PTC is amongst one of the advance concentrating thermal technologies. However, PTC application is limited to medium and elevated temperature range, that is, from $150-300^{\circ} \mathrm{C}$ and $300-400^{\circ} \mathrm{C}$, respectively [2]. In this regard, various numerical and experimental research studies have been conducted on design and development of PTC. In a research study, the thermo-mathematical model was proposed using differential and nonlinear algebraic correlations with a concentration ratio of 9.37 [3]. The results were in good agreement with experimental data of the Sandia National Laboratory (SNL). In another study, model development of PTC with the concentration ratio of 12.7 and its simulation in solid works was carried out by using finite element method. Heat transfer phenomenon and efficiency of the system were predicted and compared with the model [4]. Similarly, a detailed numerical model based on the finite volume method was developed to analyze the heat transfer characteristics of the evacuated receiver tube [5]. By using 
discretization technique, the receiver was divided into small segments and energy balance was applied to each control volume. The model was tested against test results of the Sandia National Laboratory. Moreover, a complex dynamic model of PTC and its dynamic simulations for validation were presented with root mean square error of $1.2 \%$ [6]. Likewise, a novel parabolic trough solar collector model results were validated with published data from the National Renewable Energy Laboratory (NERL) and Sandia National Laboratory (SNL) [7]. It was observed that the developed model reduced the uncertainty from $1.11 \%$ to $0.64 \%$ as compared to the EES code by NREL. Similarly, in another study, a numerical model was developed to study the thermal behavior of the single and double pass receiver tube of PTC [8]. Numerical analysis revealed that double pass tube results in enhanced thermal efficiency as compared to the single pass.

The climate conditions in term of solar radiation intensity and availability strongly influence the performance of PTC systems. Hence, a research study was conducted to access the potential of PTC for industrial heat application in Cyprus using TRNSYS [9]. The system was capable to meet $50 \%$ of annual load and proved the viability of the system for high-energy consuming industries. Additionally, E-W tracking was preferred in terms of energy gain over $\mathrm{N}-\mathrm{S}$ for Mediterranean climate. A similar research study was conducted to estimate the solar thermal potential and PTC performance for Algeria [10]. Heat transfer and temperature evolutions were compared for different climates. The hot desert climate was declared the best suitable for PTC.

Moreover, an experimental study was conducted, according to ASHRAE 93-1986 standard using fiberglass-reinforced PTC for hot water application [11]. A test methodology was developed to investigate the effect of different operating parameters on thermal efficiency.

Keeping in view the intermittent nature of solar energy resource, a research study was conducted to access the annual performance of mini PTC [12]. A nonevacuated tube with glass cover and black paint coating was applied in the model for transient analysis. The collector achieved maximum instantaneous efficiency of $66.78 \%$. Similarly, a quasidynamic simulation model in TRNSYS was developed to analyze the performance of PTC for a direct steam generation [13]. The basic modeling approach and results comparison were discussed in the study.

However, from literature review, it is seen that the majority of the abovementioned systems are high concentration ratio PTCs which produce high temperatures, associated with high cost. Furthermore, these PTCs are not compatible with hot water applications like air-conditioning due to strong space constraints subjected to commercial and industrial buildings [14]. Moreover, geographically, Pakistan is located such that more than $95 \%$ of its area receives an average global irradiance of $5-7 \mathrm{kWh} / \mathrm{m}^{2} /$ day with an average daily sunshine period of 7.6 hours [15-17]. Although abundant solar energy is available in Pakistan, no such study exists to highlight solar thermal potential using PTC technology. Therefore, in this research work, a small parabolic trough collector (PTC) is proposed for solar assisted dehumidification applications, which required hot water temperature ranging from $70-90^{\circ} \mathrm{C}$. Hence, the small and efficient PTC makes it favorable for roof-mounted hot water applications. Keeping in view the specific application of solar-assisted dehumidification, a group of four small PTC systems is designed with a concentration ratio as low as 9.93 to produce around $3 \mathrm{~kW}$ of thermal energy. Furthermore, the developed polished stainless steel PTC system is analyzed numerically and experimentally under a wide range of operating conditions for dehumidification application.

\section{Thermal Model}

Thermal design of the proposed system is based on calculations of trough focal point, rim angle, and concentration ratio. Furthermore, heat characteristics of the evacuated tube receiver are also calculated in terms of heat loss coefficient, radiation coefficient, overall heat transfer coefficient, and useful heat gain.

The optical efficiency of the receiver is calculated as [18]

$$
\eta_{\mathrm{o}}=\rho \tau \alpha \gamma\left[\left(1-A_{\mathrm{f}} \tan (\theta)\right) \cos (\theta)\right] .
$$

2.1. Receiver. In the current study, an evacuated tube is used so that negligible convection losses are encountered. Thermal resistance model of the PTC is given in Figure 1. The heat loss coefficient of the receiver is determined by [18]

$$
U_{\mathrm{rl}}=\left[\frac{A_{\mathrm{r}}}{\left(h_{\mathrm{w}}+h_{(r, c-a)}\right) A_{\mathrm{c}}}+\frac{1}{h_{r,(r-c)}}\right]^{-1} .
$$

Radiation coefficient from the absorber to glass cover is obtained from [18]

$$
h_{(r, c-a)}=\frac{\sigma\left(T_{\mathrm{r}}^{2}+T_{\mathrm{c}}^{2}\right)\left(T_{\mathrm{r}}+T_{\mathrm{c}}\right)}{\left(\left(1 / \varepsilon_{\mathrm{r}}\right)+\left(A_{\mathrm{r}} / A_{\mathrm{c}}\right)\right)\left(1 / \varepsilon_{\mathrm{c}}-1\right)} .
$$

Overall heat transfer coefficient is calculated by considering tubes outer and inner diameter as [9]

$$
U_{\mathrm{o}}=\left[\frac{1}{U_{\mathrm{rl}}}+\frac{D_{\mathrm{o}}}{\left(h_{\mathrm{fi}} D_{\mathrm{i}}\right)}+\frac{D_{\mathrm{o}} \ln \left(D_{\mathrm{o}} / D_{\mathrm{i}}\right)}{2 k}\right]^{-1} .
$$

Nusselt number is calculated from the standard pipe flow equation as [19]

$$
\mathrm{Nu}=0.023(\operatorname{Re})^{0.8}(\operatorname{Pr})^{0.4}
$$

The collector efficiency factor is given by [18]

$$
F^{\prime}=\frac{1 / U_{\mathrm{rl}}}{\left[\left(1 / U_{\mathrm{rl}}\right)+\left(D_{\mathrm{o}} / h_{\mathrm{fi}} D_{\mathrm{i}}\right)+\left(\left(D_{\mathrm{o}} / 2 k\right) \ln \left(D_{\mathrm{o}} / D_{\mathrm{i}}\right)\right)\right]} .
$$

Collector heat removal factor is the ratio of actual useful energy gain to maximum energy gain as [18]

$$
F_{\mathrm{r}}=\frac{\dot{m} c_{p w}}{A_{\mathrm{r}} U_{\mathrm{rl}}}\left[1-\exp \left(-\frac{U_{\mathrm{rl}} F^{\prime} A_{\mathrm{r}}}{\dot{m} c_{p w}}\right)\right] \text {. }
$$




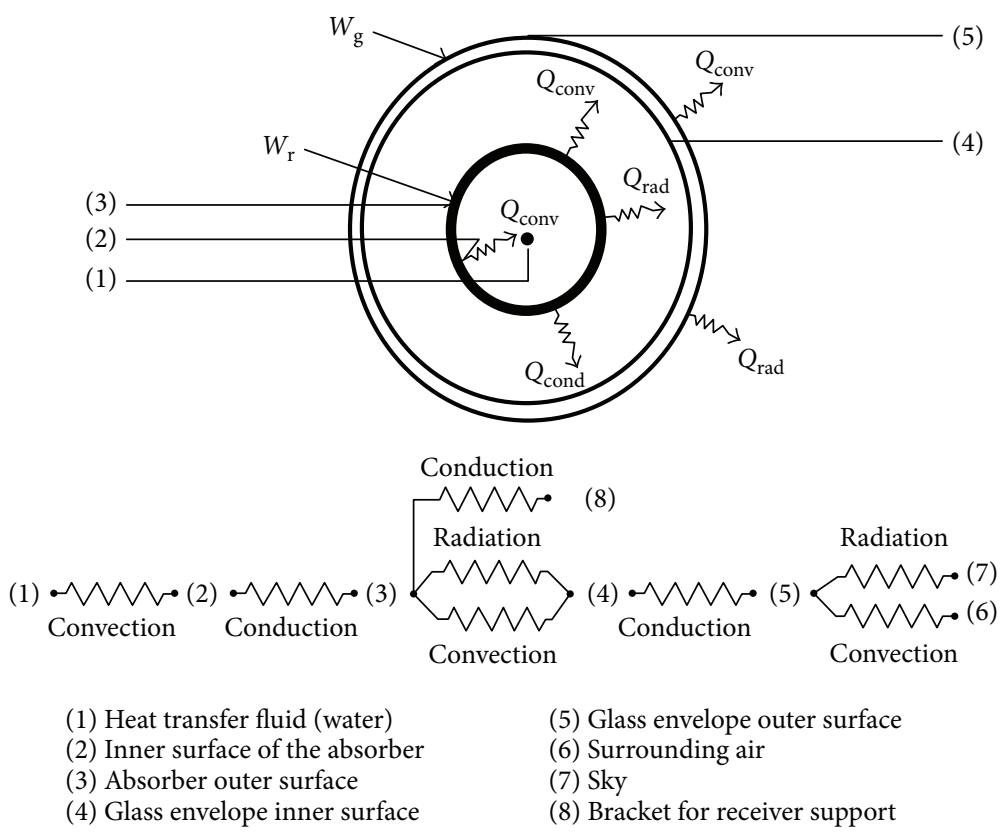

Figure 1: Thermal resistance model of the PTC.

2.2. Useful Heat Gain. Useful energy delivered from PTC is obtained through efficiency factor of the receiver along with incidence angle modifier determined by applying energy balance to the receiver [20]:

$$
Q_{\mathrm{u}}=F_{\mathrm{r}}\left[I_{\mathrm{b}} \eta_{\mathrm{o}} A_{\mathrm{a}}-A_{\mathrm{r}} U_{\mathrm{rl}}\left(T_{\mathrm{in}}-T_{\mathrm{a}}\right)\right] .
$$

Here, to determine the dependency of the incidence angle modifier (IAM) on an angle of incidence, correlation is developed. The correlation is obtained through the application of polynomial curve fitting on experimental data as presented in Figure 2(b).

$$
K_{\theta}=-\left(5.0^{*} 10^{-6}\right) \theta^{3}+\left(2^{*} 10^{-4}\right) \theta^{2}-\left(4^{*} 10^{-3}\right) \theta+1.001,
$$

whereas the instantaneous thermal efficiency of PTC is found by [21]

$$
\eta=\frac{Q_{\mathrm{u}}}{I_{\mathrm{b}} A_{\mathrm{a}}}
$$

Finally, outlet temperature of the PTC is found by [18]

$$
T_{\mathrm{o}}=T_{\mathrm{in}}+\frac{Q_{\mathrm{u}}}{\dot{m} c_{p w}} .
$$

The above design calculations of the system are performed through the development of a mathematical model in the engineering equation solver (EES) [22] due to its coupling compatibility with TRNSYS [23]. The flow chart of the thermodynamic model is presented in the Figure 3.

2.3. Data Reduction. By using various equations and correlations, data is reduced for analysis and graphical representation.

The heat energy gain of the PTC is defined as

$$
Q_{\mathrm{u}}=\dot{m} c_{\mathrm{p}}\left(T_{\mathrm{o}}-T_{\mathrm{in}}\right) .
$$

Therefore, the instantaneous efficiency of PTC in each case can be calculated by [20]

$$
\eta=\frac{Q_{\mathrm{u}}}{A_{\mathrm{a}} I_{\mathrm{b}}}=\frac{\dot{m} c_{\mathrm{p}}\left(T_{\mathrm{o}}-T_{\mathrm{in}}\right)}{A_{\mathrm{a}} I_{\mathrm{b}}} .
$$

However, thermal efficiency related to the parameters from data points is given by [18]

$$
\eta=F_{\mathrm{r}}\left[\eta_{\mathrm{o}}-\frac{U_{\mathrm{rl}}}{C}\left(\frac{T_{\mathrm{in}}-T_{\mathrm{a}}}{I_{\mathrm{b}}}\right)\right]=a+b T^{*}
$$

where

$$
\begin{aligned}
T^{*} & =\frac{T_{\mathrm{in}}-T_{\mathrm{a}}}{I_{\mathrm{b}}}, \\
a & =F_{\mathrm{r}} \eta_{\mathrm{o}}, \\
b & =\left(-\frac{F_{\mathrm{r}} U_{\mathrm{rl}}}{C}\right) .
\end{aligned}
$$

Moreover, incidence angle modifier (IAM) is determined as a ratio of instantaneous thermal efficiency at an angle of incidence to peak thermal efficiency as $[24,25]$

$$
\mathrm{IAM}=\frac{\eta\left(T_{\mathrm{in}}=T_{\mathrm{a}}\right)}{F_{\mathrm{r}}\left(\eta_{\mathrm{o}}\right)} .
$$

Collector time constant is the time needed by the PTC to change the temperature of the working fluid, $63.2 \%$ of its steady-state value when a step change in the incident radiation occurs [26]. 


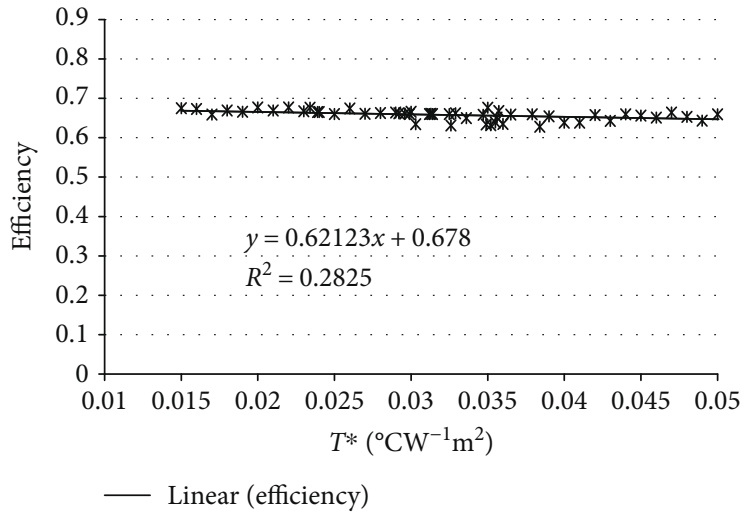

(a)

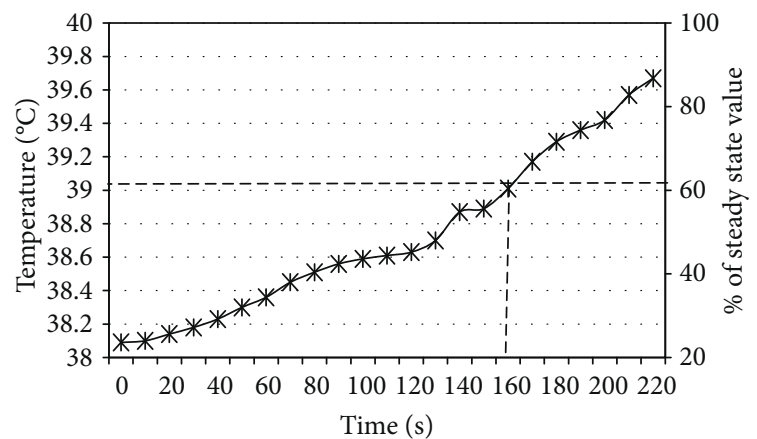

(c)

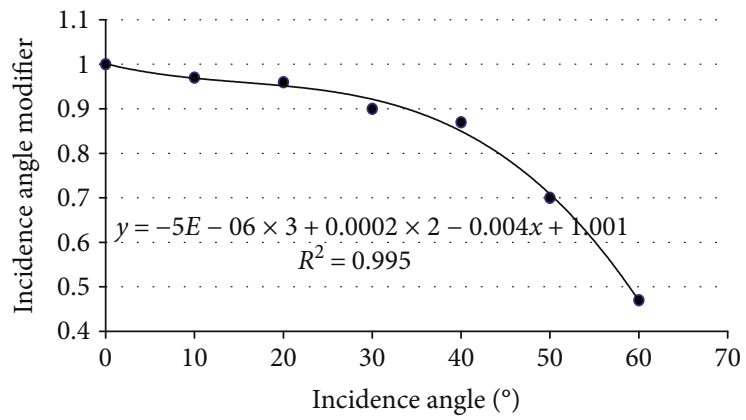

(b)

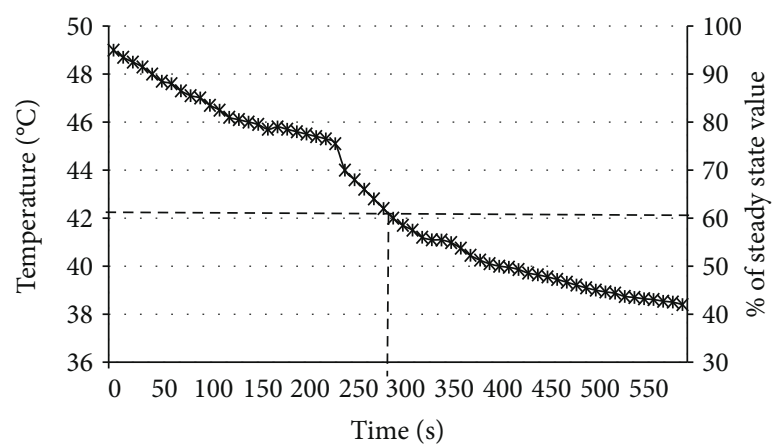

(d)

FIgure 2: Thermal performance according to ASHRAE standard. (a) Efficiency test, (b) incidence angle modifier, (c) PTC heating time constant, and (d) PTC cooling time constant.

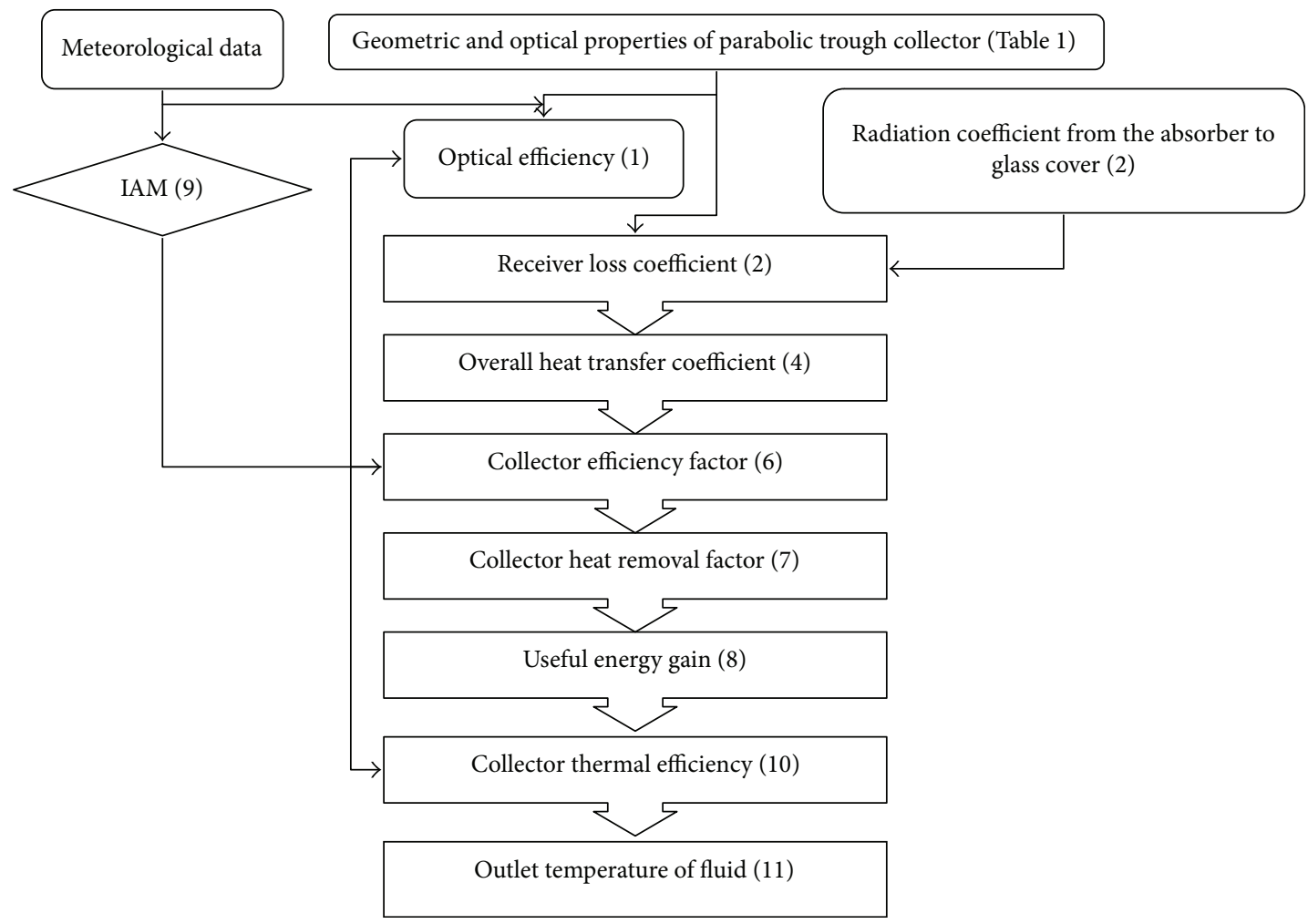

FIGURE 3: Flowchart of the thermodynamic model. 


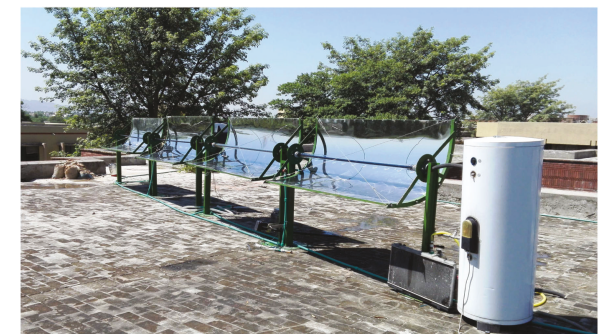

FIGURE 4: Roof-mounted PTCs with accessories for hot water production.

The time constant test for thermal collectors represents the thermal inertia of the receiver or its heat capacity.

The time constant for heating and cooling is given by [27]

$$
\frac{T_{\mathrm{o}}-T_{\mathrm{in}}}{T_{\mathrm{oi}}-T_{\mathrm{in}}}=\frac{1}{e}=0.367 .
$$

Finally, root mean square error value is determined by [28]

$$
\text { RMSE }=\sqrt{\frac{\sum_{i=1}^{n}\left(X_{\text {exp }}-X_{\text {model }}\right)^{2}}{n}} .
$$

The solar fraction of the PTC system is defined as

$$
\mathrm{SF}=\frac{Q_{\text {sol }}}{Q_{\text {total }}},
$$

where $Q_{\text {sol }}$ is the solar energy gain from PTCs and $Q_{\text {total }}$ is the sum of solar energy as well as the auxiliary energy from the electric heaters.

Moreover, the dehumidification share (DS) is the product of solar fraction and total dehumidification effect produced given as

$$
\mathrm{DS}=\mathrm{SF}\left(D_{\mathrm{e}}\right),
$$

where $D_{\mathrm{e}}$ is the total dehumidification effect of the desiccant wheel.

\section{Material and Methods}

This section comprises of the experimental setup, measurement procedure, and correlations used in the current study.

3.1. Experimental Setup. Experimental structure is fabricated for real-time analysis, based on the design parameters obtained through EES model processing. The setup consists of an array of four PTCs, working fluid circuit, and sensing and measuring instruments as presented in Figure 4.

The polished stainless steel sheet of $2 \times 1 \mathrm{~m}^{2}$ is used as a reflector medium for each trough. The sheet is properly bent to achieve the desired designed concentration ratio of 9.93 and focal point $0.210 \mathrm{~m}$. In total, four PTC units in series are used when analyzing the transient and real-time system performance. The evacuated tube receiver consists of a copper tube $2 \mathrm{~m}$ long with outer and inner diameters of $0.21 \mathrm{~m}$ and $0.19 \mathrm{~m}$, respectively, with the selective coating. Single axis E-W tracking was accomplished by solar tracking kit consisting of sunlight sensor and solar tracker linear actuator. The absorber tube is covered by borosilicate glass with a thickness of $0.004 \mathrm{~m}$.

The other major component of the experimental setup is the solid desiccant dehumidifier as shown in Figure 5. The design parameters and overall system specifications of PTCs and solid desiccant wheel are given in Table 1. The hot water stratified storage tank with polyurethane insulation equipped with an electric heater is used for water circulation. The setpoint temperature for the electric heater is $80^{\circ} \mathrm{C}$. The hot water is drawn from the top of the tank and supplied to the heating coil. The ambient air at stage 1 passes through the heating coil and after regenerating the desiccant wheel leaves the system at stage 2. Similarly, the humid air enters the dehumidification system at stage 3 , dehumidified and leaves the system at stage 4 .

3.2. Measurement Procedure. The experiments are conducted at RERDC (Renewable Energy Research and Development Center) located in Taxila (latitude $33.7370^{\circ} \mathrm{N}$ and longitude $72.7994^{\circ} \mathrm{E}$ ). Figure 5 shows the schematic of experimental setup with measuring and sensing instruments. In the current study, various climate, inlet, and outlet parameters are continuously measured with a time interval of 10 minutes. The parameters include direct solar radiation, ambient temperature, wind velocity, water temperature, air humidity, and mass flow rate.

Operating water temperatures are measured by using $\mathrm{K}$ type thermocouples with a sensitivity of $0.01^{\circ} \mathrm{C}$. Refrigerated bath circulator model WCR-P12 is used for calibration, with standard thermocouple PT100, calibration range $-20^{\circ} \mathrm{C}$ to $120^{\circ} \mathrm{C}$, and accuracy of $\pm 0.01^{\circ} \mathrm{C}$. Digital flow transducer S8011R was used to measure mass flow rate in the range of $50-1000 \mathrm{~kg} / \mathrm{h}$, whereas climate data including wind velocity and solar radiations are measured through hot wire anemometer and pyrheliometer model TBS-2-2 with a spectral range of $280-3000 \mathrm{~nm}$ and sensitivity of $9.876 \mu \mathrm{V} / \mathrm{Wm}^{-2}$. Moreover, the temperature and humidity of the air are measured by using Pro-dual sensors (KLK-100). Hot wire anemometer is used to measure the velocity of the air in the duct. Experiments were conducted from 9:00 AM to 6:00 PM in each case with a fixed mass flow rate of $480 \mathrm{~kg} /$ hr., average wind velocity below $1 \mathrm{~m} / \mathrm{s}$, ambient temperature within $\pm 3 \%$ of $30^{\circ} \mathrm{C}$, and absolute humidity of $16 \mathrm{~g} / \mathrm{kg}$ within $\pm 3 \%$. Climate data was recorded in the Jinzhou Sunshine Science Data collector unit model TRM-Zs1.

3.3. Transient Analysis. Transient analysis is performed by coupling the EES model with TRNSYS through Type 66a. In the current study, the same EES model of PTC with some modifications is used, as discussed in the previous section. Though the TESS library for TRNSYS also contains linear parabolic concentrator model, the EES model is preferred due to certain limitations of Type 536. As intercept efficiency in Type 536 is declared as a parameter which remains constant throughout simulations, while in the developed model, Eq. 8 is used for useful heat gain for dependency of all variables on transient inputs and its greater accuracy during 


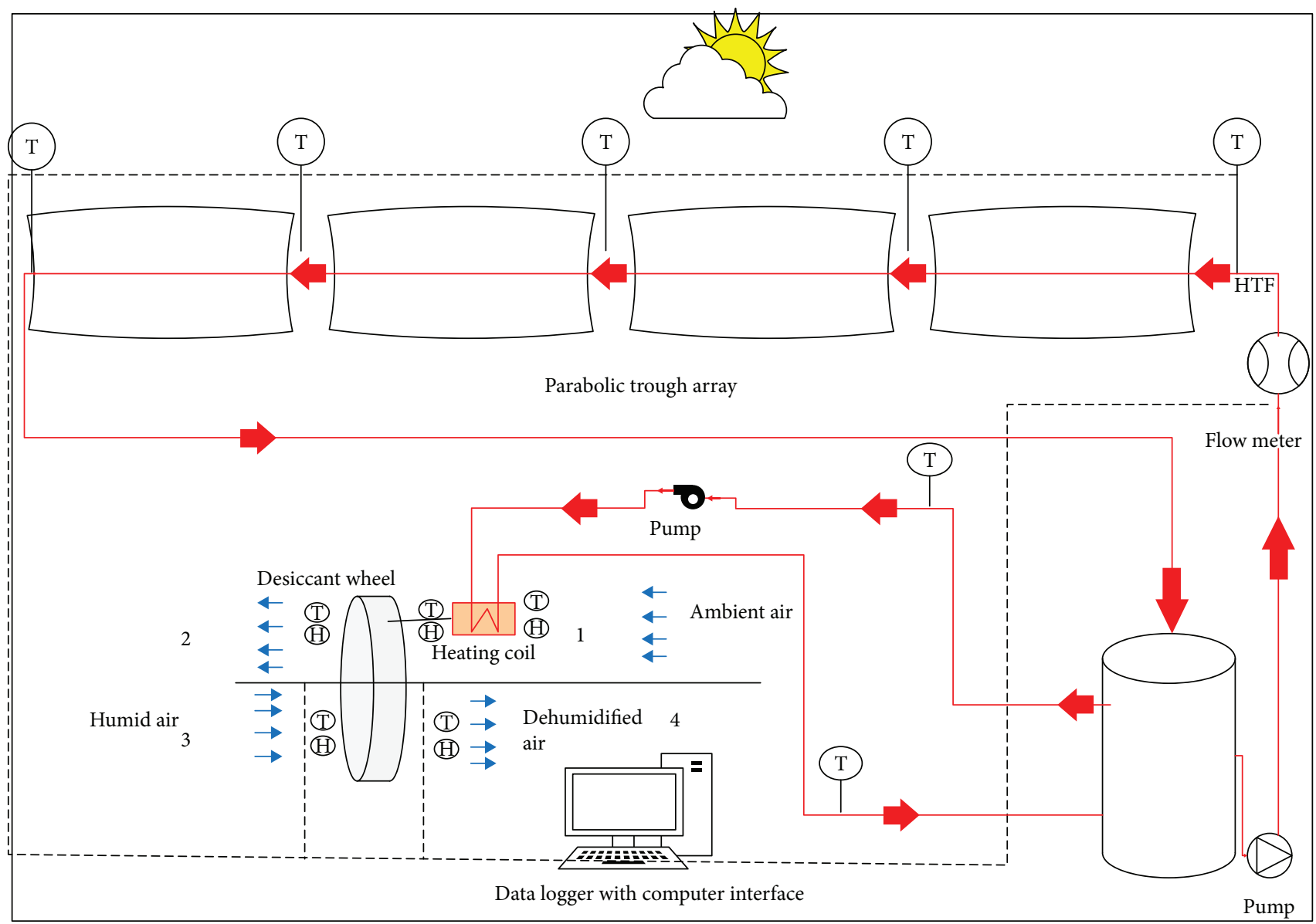

FIGURE 5: Schematic of experimental setup with sensing and measuring instruments.

model validation. Various components (types) are used to generate and process input data along with some outputs. The hourly climate data such as ambient temperature, radiations, and incidence angle based on TMY files are incorporated through Type 15 . In addition, the time schedule is implemented from 9:00 AM to 6:00 PM. Equation 1 in the simulation studio is used for conversion of direct solar radiations from $\mathrm{kJ} / \mathrm{hr}$ to $\mathrm{W} / \mathrm{m}^{2}$ and to calculate IAM values for respective incidence angles. Major components include Type 683 for the solid desiccant wheel model, Type 667 for heat recovery, and Type $4 \mathrm{~b}$ for a stratified storage tank. The detailed description of the components can be found in the standard TRNSYS manual [23]. Furthermore, monthly useful energy gain is determined by applying an integrator that integrates hourly into monthly outcomes. The output performance parameters, for example, water outlet temperature, useful heat gain, and system efficiency are extracted from the model by using various output components such as printer and plotters as shown in Figure 6. The annual transient simulations are performed by using TMY data for the climate conditions of Taxila, Pakistan. Furthermore, potential assessment for various other cities is also executed with the help of TMY data files [23]. The simulation interval is one hour and executed by using successive substitution solution method with tolerance convergence of 0.0001 .
The transient analysis follows almost similar approach as described in the experimental setup with some slight modifications and control strategies. The cold water from the base of the stratified tank is circulated through a pump to the PTC array. The model then calculates thermal energy gain and outlet temperatures based on the given climate data. A differential controller governs the working of the pump with a predefined temperature band of $10^{\circ} \mathrm{C}$. Tempering valve restricts the temperature of the outlet stream of supplied water from exceeding the set point temperature. Due to the intermittent nature of the solar energy, an auxiliary gas heater is added in the flow stream. The hot water passes through the heating coils and after exchanging the heat, it returned to the hot water tank again. The regeneration air after passing through the heat recovery wheel absorbs this heat for achieving the desired regeneration temperature. This hot air hence regenerates the desiccant wheel.

\section{Results and Discussion}

Initially, the thermal performance of PTC is evaluated with different experimental tests according to ASHRAE 93-1986 standard [26] for procedural validation. Afterwards, further detailed experimental analysis categorized in two cases is performed, in terms of temperature variation, useful heat gain, 
TABle 1: Parameters for parabolic trough collector and desiccant wheel.

\begin{tabular}{lc}
\hline Parameter & Value \\
Aperture length $(\mathrm{m})$ & 2.1 \\
Aperture width $(\mathrm{m})$ & 1.067 \\
Focal distance $(\mathrm{m})$ & 0.211 \\
Aperture area $\left(\mathrm{m}^{2}\right)$ & 2.077 \\
Concentration ratio & 9.93 \\
Rim angle $\left({ }^{\circ}\right)$ & 108 \\
Reflector sheet thickness $(\mathrm{m})$ & 0.0005 \\
Reflectance of surface & 0.89 \\
Transmittance of glass & 0.90 \\
Length of receiver $(\mathrm{m})$ & 2.0 \\
Absorptance of the receiver & $>93 \%$ \\
Outer glass tube diameter $(\mathrm{m})$ & 0.123 \\
Outer glass tube thickness $(\mathrm{m})$ & 0.002 \\
Inner tube diameter $(\mathrm{m})$ & 0.003 \\
Inner tube thickness $(\mathrm{m})$ & 0.0013 \\
Conductivity of tube $(\mathrm{W} / \mathrm{m} \mathrm{K})$ & 380 \\
Emittance of tube & $<7 \%$ \\
\hline Desiccant wheel & \\
Regeneration rage of desiccant wheel & $60-120^{\circ} \mathrm{C}$ \\
Rotation speed & $20 \mathrm{RPH}$ \\
Effectiveness & $55 \%$ at $80^{\circ} \mathrm{C}$ \\
Diameter of the wheel & $350 \mathrm{~mm}$ \\
Wheel length & $200 \mathrm{~mm}$ \\
Design capacity & $800 \mathrm{~kg} / \mathrm{hr}$ \\
\hline
\end{tabular}

and thermal efficiency of PTC integrated with a solid desiccant dehumidifier under a fixed mass flow rate of $480 \mathrm{~kg} / \mathrm{hr}$.

It can be observed that thermal efficiency $\eta$ is a linear function of $T^{*}$ as shown in Figure 2. The slope and the intercept of the $\eta$ linear fit are represented as "a," "b," and given by (16) and (17), respectively.

To acquire the best fit straight line, the least square fitting technique is used through the set of efficiency points. The PTC thermal efficiency is determined as

$$
\eta=0.678-0.6213 T^{*} .
$$

Heat losses of the collector are steady when compared to the temperature of the working fluid. The curve shows that when the inlet fluid temperature is nearby the ambient temperature, the collector efficiency is around 67\% which is in agreement with published data comparable with other PTCs efficiency designed and tested for medium temperature ranges [29]. However, $\eta$ in the present work is closer to the smallest concentration ratio collector present in the literature by Coccia et al. [30].

Similarly, Figure 2(b) represents the incidence angle modifier variation with respect to the incidence angle. As the angle of incidence increases, the incidence angle modifier decreases. A third order polynomial equation is obtained for IAM, by applying curve fitting for its further application in model validation and transient analysis as given in (9). The determination coefficient $\left(R^{2}\right)$ for curve fitting is 0.99 .

The PTC heating and cooling time constant are $160 \mathrm{~s}$ and $270 \mathrm{~s}$, respectively, as presented by Figures 2(c) and 2 (d), respectively.

\subsection{Experimental Analysis}

4.1.1. Case 1: Sunny Day. In the current work, the experimental analysis of the PTC integrated with the solid desiccant dehumidifier (SDD) is determined and discussed as follows.

Variation of water inlet temperature and outlet temperature along with temperature difference is shown in Figure $7(\mathrm{a})$. The increase in incident radiations positively effects the outlet temperature of the water. Variation of inlet temperature during the day is from $72^{\circ} \mathrm{C}$ to $77^{\circ} \mathrm{C}$. The inlet and outlet temperature of the working fluid progressively increases from 9:00 AM and reaches its peak around 2:30 PM. Similarly, working fluid temperature difference at inlet and outlet also exhibits the same trend of progressive increment till 2:00 PM. The maximum value of the outlet temperature is $84^{\circ} \mathrm{C}$ at $2: 30 \mathrm{PM}$. Furthermore, maximum and minimum temperature difference achieved is $5.52^{\circ} \mathrm{C}$ and $1.5^{\circ} \mathrm{C}$, respectively. The experimental instantaneous thermal efficiency of PTC along with corresponding EES model results are shown in Figure 7(b). Experimental data shows that efficiency $(\eta)$ bears minimum values during the morning and afternoon.

Whereas the maximum value of $\eta$ is about $62 \%$ at $1: 20 \mathrm{PM}$, the reason for the variation is that the instantaneous efficiency is maximized when direct solar radiations are at its peak and incidence angles are small. Minimum instantaneous efficiency value is $19 \%$ at 6:00 PM. Moreover, comparative analysis of experimental data and model results are in good agreement with root mean square error value of about $9 \%$.

Similarly, the hourly energy flows and solar fraction of the system is presented in Figure 7(c). It can be observed that the system thermal demand for dehumidification varies from 2 to $2.83 \mathrm{~kW}$.

Similarly, solar energy gain also varies from 0.62 to $3 \mathrm{~kW}$. Peak solar energy gain occurs corresponding to incident beam radiations of $5 \mathrm{kWh}$. Moreover, solar fraction also starts increasing in the morning till it reaches one at 12:00 AM; however, it starts decreasing after 3:00 PM.

Finally, dehumidification share of PTC is highlighted in Figure 7(d). It can be observed that dehumidification share of the PTC varies from 1.7 to $6.4 \mathrm{~g} / \mathrm{kg}$ depending on the availability of solar radiations.

4.1.2. Case 2: Cloudy Day. The outlet temperature of the fluid and temperature difference at inlet and outlet fluctuates along the day corresponding to the intensity of solar radiations, as highlighted in Figure 8(a).

Maximum outlet temperature and temperature difference achieved are $80^{\circ} \mathrm{C}$ and $4.2^{\circ} \mathrm{C}$, respectively. The average outlet temperature of the water is $78^{\circ} \mathrm{C}$. 


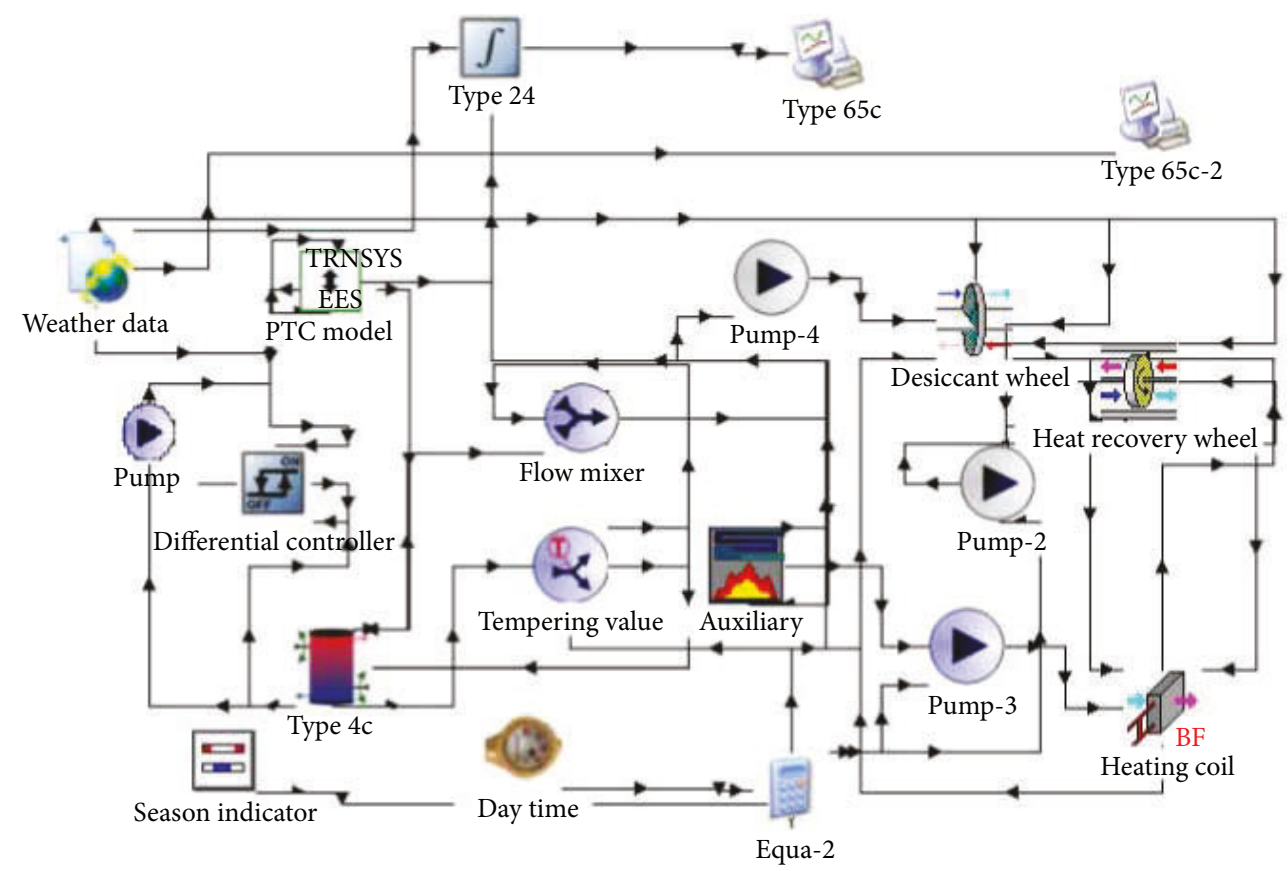

FIGURE 6: Transient simulation model in TRNSYS coupled with EES.

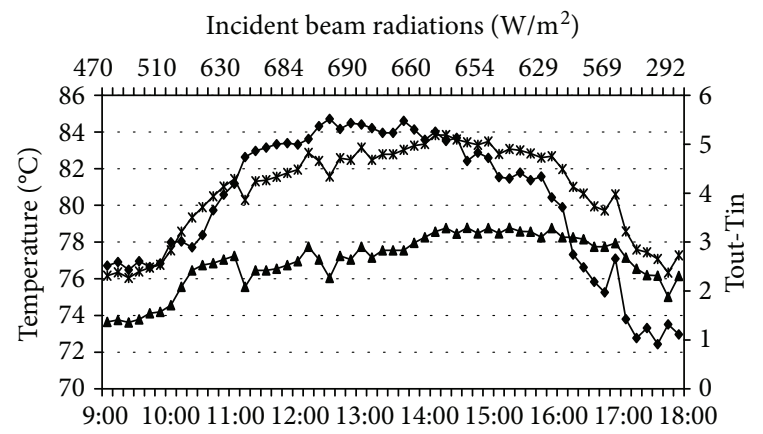

Time (hrs)

$\rightarrow$ Tin

* Tout

$\rightarrow$ Tout-Tin

(a)

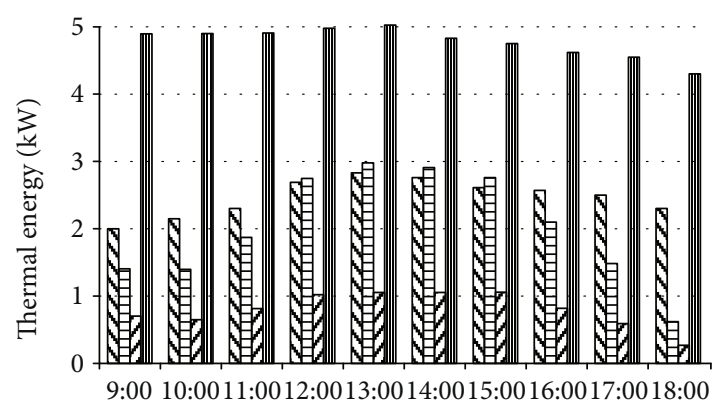

Time (hrs)

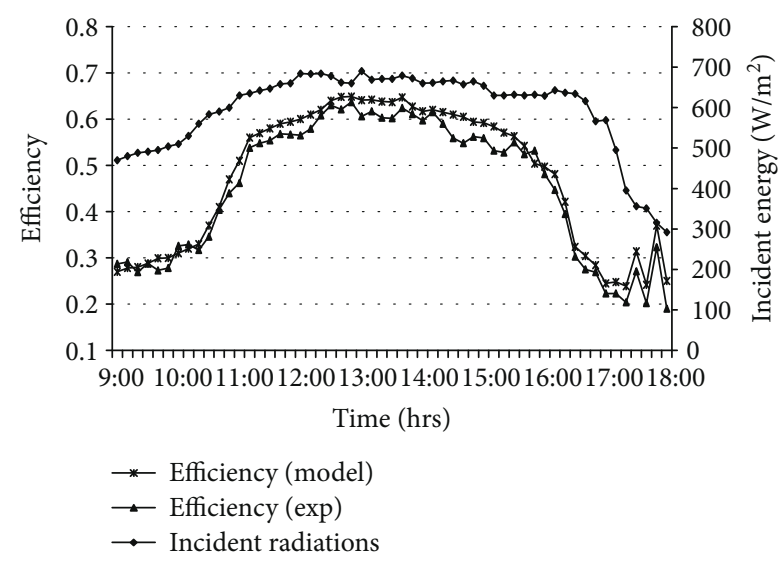

(b)

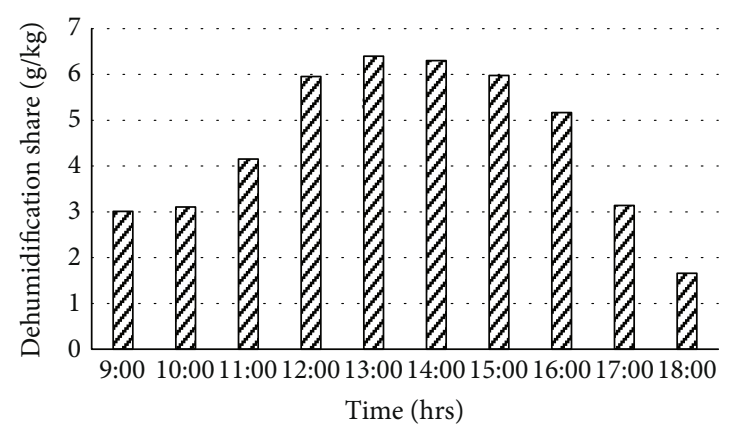

(d)

Figure 7: Sunny day. (a)Variation of collector temperatures. (b) Variation of collector efficiency along with model results. (c) Evolution of energy and solar fraction. (d) Dehumidification share of PTC. 


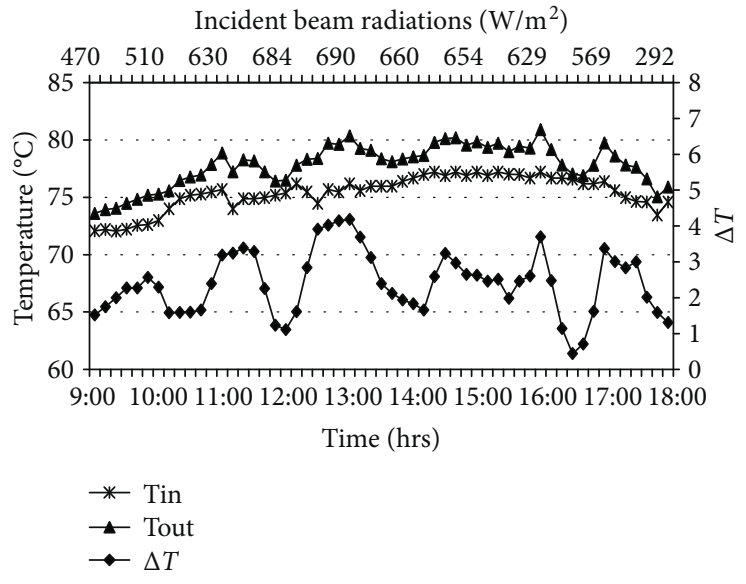

(a)

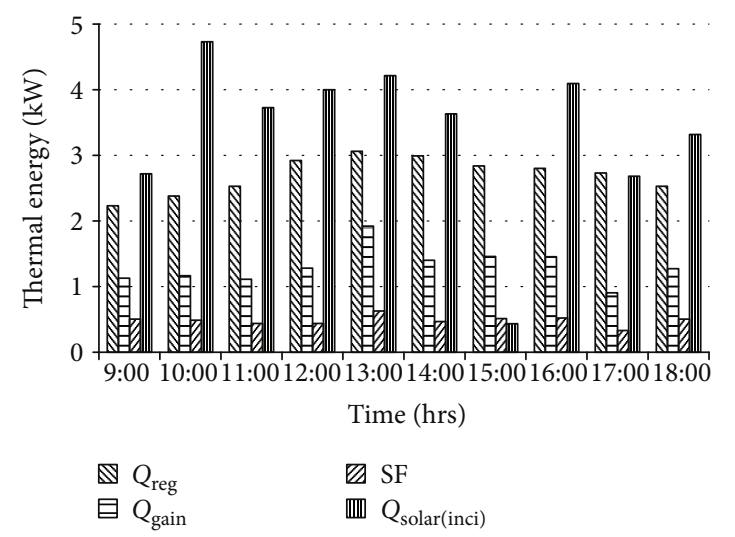

(c)

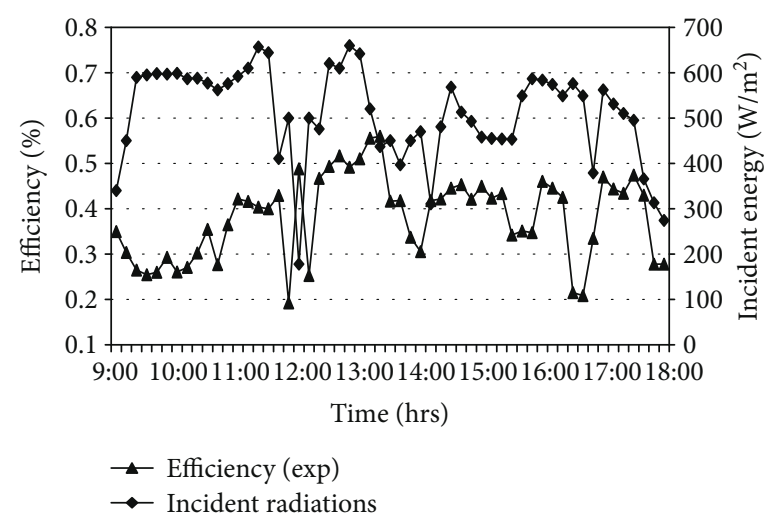

(b)

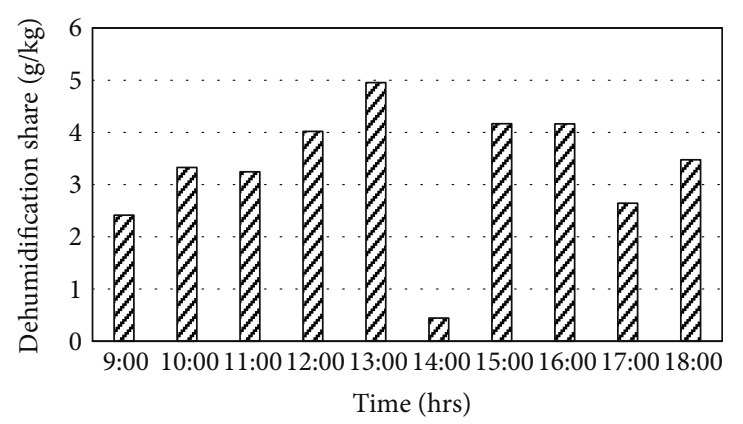

(d)

Figure 8: Cloudy day. (a) Variation of collector temperatures. (b) Variation of collector efficiency along with model results. (c) Evolution of energy and solar fraction. (d) Dehumidification share of PTC.

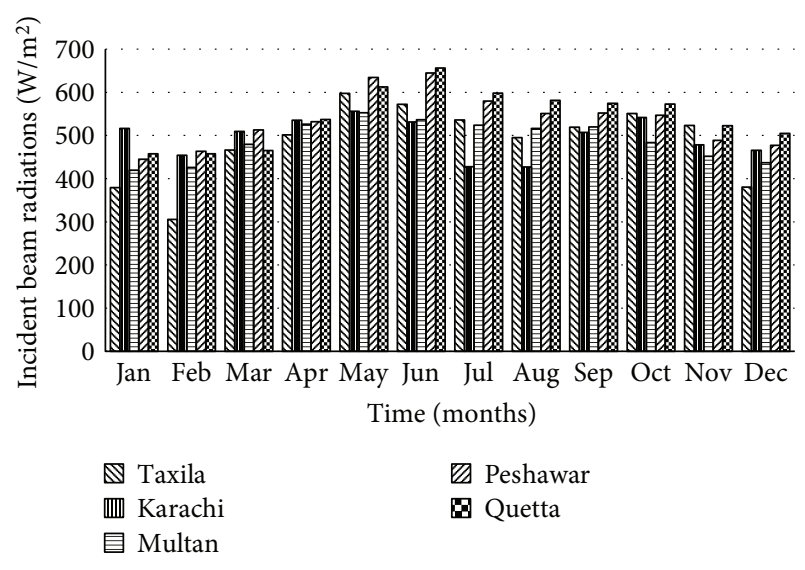

FIGURE 9: Evolution of monthly average direct solar radiations.

Cloudy day is associated with abrupt changes in solar flux between $170 \mathrm{~W} / \mathrm{m}^{2}$ and $700 \mathrm{~W} / \mathrm{m}^{2}$ as highlighted in Figure $8(\mathrm{~b})$. The maximum value for incident direct solar radiations is $700 \mathrm{~W} / \mathrm{m}^{2}$ at 9:20 $\mathrm{AM}$; moreover, the efficiency of PTC during a cloudy day is also presented in Figure 8(c).
The maximum value of efficiency in a cloudy day is up to $56.6 \%$ corresponding to $331 \mathrm{~W} / \mathrm{m}^{2}$ at $1: 30 \mathrm{PM}$.

Similarly, the system energy flows along with solar fraction are presented in Figure 8(c).

The incident solar radiations and hence the solar energy gain constantly fluctuate along the day; however, heat gain is small due to greater incidence angle of the incidence in the morning. Although, the maximum incident energy of 4.72 kWh occurs at 10:00 AM but maximum heat gain of $1.92 \mathrm{~kW}$ is achieved corresponding to incident energy of $4.21 \mathrm{kWh}$ at 1:00 PM. So, it is also evident from the comparison that incident direct solar radiations along with incidence angle strongly influence the useful heat gain of PTC.

Moreover, Figure $8(\mathrm{~d})$ presents the dehumidification share of the PTC during a cloudy day. It is evident that it exhibits almost similar trends as solar energy gain in Figure $8(\mathrm{c})$. The maximum and minimum values for dehumidification share are $5.0 \mathrm{~g} / \mathrm{kg}$ and $0.6 \mathrm{~g} / \mathrm{kg}$, respectively.

4.2. Transient Analysis. The PTC system is further subjected to annual transient analysis and is highlighted from Figures $9-11$ by adopting the methodology given in Section 2.3 . 


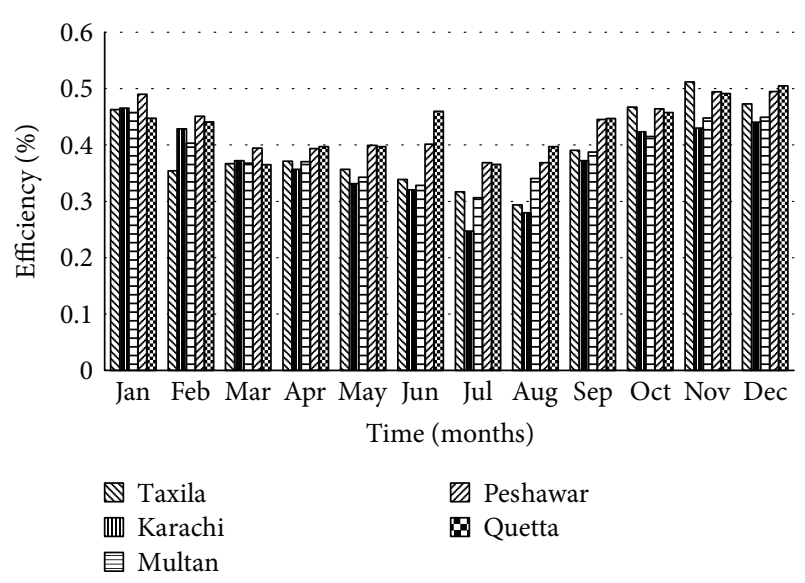

Figure 10: Monthly average efficiency variation of PTC.

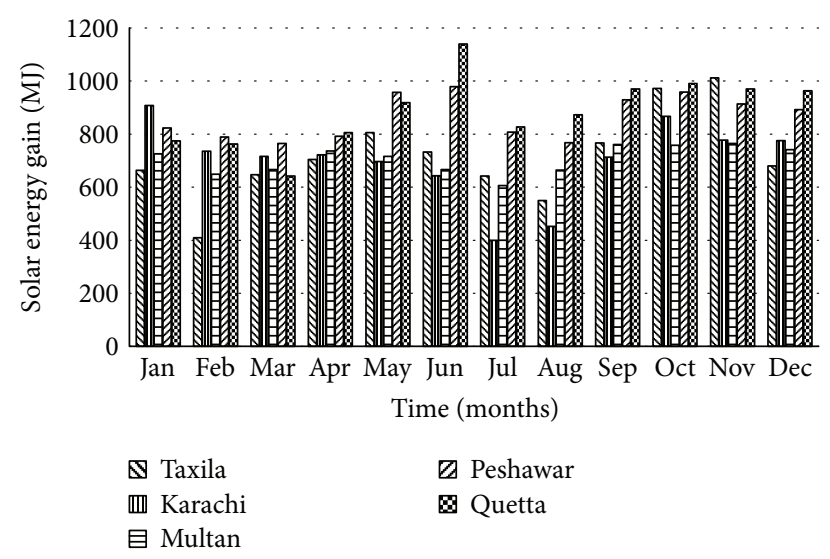

FIgURE 11: Monthly average solar energy gain of integrated PTC.

Monthly average direct solar radiations trends are presented in Figure 9 for five major cities of Pakistan. It is evident from the intensity of solar radiations that considerable potential for solar thermal application exists in the country. Maximum value of direct solar radiations is up to $656 \mathrm{~W} / \mathrm{m}^{2}$ for Quetta in June. However, minimum monthly average value exists for Taxila in February, that is, $453 \mathrm{~W} / \mathrm{m}^{2}$.

It can also be observed that monthly average values for efficiency vary from 24 to $51 \%$ as shown in Figure 10 . Collector efficiency is maximum in Quetta due to better available irradiance while minimum in the humid climate of Karachi.

Finally, monthly average solar energy gain for different climates is presented in Figure 11. It is evident that maximum monthly average useful energy gain of $1140 \mathrm{MJ}$ is achieved in June for Quetta, while minimum value is $408 \mathrm{MJ}$ in February.

\section{Conclusions}

The experimental investigation of a small-sized parabolic trough collector for the solar dehumidification purpose has been carried out in the current study. The following conclusions have been drawn from the investigation: (i) The experimental results are compared with those measured from the mathematical model. Various tests conducted according to ASHRAE standard determined that the maximum instantaneous thermal efficiency of the collector is $67 \%$.

(ii) The intercept and the slope determined by the PTC efficiency curve are found to be 0.67 and 0.62 , respectively. While the resulted PTC heating and cooling time constants are $160 \mathrm{~s}$ and $270 \mathrm{~s}$, respectively.

(iii) Detailed experimental analysis of PTC integrated with the solid desiccant dehumidifier on a sunny and cloudy day revealed maximum instantaneous thermal efficiency of $62 \%$ and $56.6 \%$, maximum temperature difference of $5.52^{\circ} \mathrm{C}$ and $4.1^{\circ} \mathrm{C}$, and maximum useful energy gain of $3.0 \mathrm{~kW}$ and $1.92 \mathrm{~kW}$, respectively.

(iv) Annual transient analysis in different cities revealed maximum monthly average efficiency up to $52 \%$ in Quetta and maximum solar energy gain around 1139 MJ. Finally, the model validation with efficiency parameter shows that a root mean square error value (RMSEV) of $9 \%$ exists. Hence, the proposed system is very much suitable for solar thermal-assisted dehumidification and airconditioning application.

\section{Nomenclature}

$\begin{array}{ll}A_{\mathrm{a}}: & \text { Aperture area }\left(\mathrm{m}^{2}\right) \\ A_{\mathrm{c}}: & \text { Glass cover area }\left(\mathrm{m}^{2}\right) \\ A_{\mathrm{r}}: & \text { Receiver area }\left(\mathrm{m}^{2}\right) \\ A_{\mathrm{f}}: & \text { Geometric factor }(-) \\ C: & \text { Concentration ratio }(-) \\ c_{p w}: & \text { Heat capacity }(\mathrm{kJ} / \mathrm{kgK}) \\ D_{\mathrm{e}}: & \text { Total dehumidification effect }(\mathrm{g}) \\ D_{\mathrm{i}}: & \text { Tube's inner diameter }(\mathrm{m}) \\ D_{\mathrm{o}}: & \text { Tube's outer diameter }(\mathrm{m}) \\ F_{\mathrm{r}}: & \text { Heat removal factor }(-) \\ F: & \text { Collector efficiency factor }(-) \\ h_{\mathrm{fi}}: & \text { Convective heat transfer coefficient inside the } \\ & \text { tube }\left(\mathrm{W} / \mathrm{m}^{2} \mathrm{~K}\right) \\ h_{r,(r-c)}: & \text { Radiation coefficient from receiver to cover } \\ h_{r,(c-a)}: & \text { Radiation coefficient from cover to ambient } \\ & \left.\text { (W/m }{ }^{2} \mathrm{~K}\right) \\ h_{\mathrm{w}}: & \text { Wind heat transfer coefficient }\left(\mathrm{W} / \mathrm{m}^{2} \mathrm{~K}\right) \\ I_{\mathrm{b}}: & \text { Incident beam radiations }\left(\mathrm{W} / \mathrm{m}^{2}\right) \\ K_{\theta}: & \text { Incidence angle modifier } \\ k: & \text { Conductivity }(\mathrm{W} / \mathrm{mK}) \\ \dot{m}: & \text { Mass flow rate }(\mathrm{kg} / \mathrm{s}) \\ n: & \text { Total number of observations } \\ \text { Nu: } & \text { Nusselt number }(-) \\ \mathrm{Pr}: & \text { Prandtl number }(-) \\ Q_{\text {cond }}: & \text { Heat transfer due to conduction }(\mathrm{W}) \\ Q_{\text {conv }}: & \text { Heat transfer due to convection }(\mathrm{W}) \\ Q_{\mathrm{rad}}: & \text { Heat transfer due to radiation }(\mathrm{W}) \\ Q_{\mathrm{sol}}: & \text { Solar energy }\left(\mathrm{W} / \mathrm{m}^{2}\right) \\ & \end{array}$


$Q_{\text {total }}: \quad$ Total energy (W)

$Q_{\mathrm{u}}: \quad$ Heat energy gain (W)

$\mathrm{R}_{\mathrm{e}}$ : $\quad$ Reynolds number (-)

SF: $\quad$ Solar fraction

$T_{\mathrm{a}}$ : Ambient temperature (K)

$T_{\mathrm{c}}$ : $\quad$ Temperature of glass cover $(\mathrm{K})$

$T_{\text {in }}$ : Inlet fluid temperature (K)

$T_{\mathrm{oi}}: \quad$ Initial outlet temperature $(\mathrm{K})$

$T_{\mathrm{o}}$ : $\quad$ Outlet fluid temperature $(\mathrm{K})$

$T_{\mathrm{r}}$ : Temperature of the receiver tube $(\mathrm{K})$

$U_{\mathrm{o}}: \quad$ Overall heat transfer coefficient $\left(\mathrm{W} / \mathrm{m}^{2} \mathrm{~K}\right)$

$U_{\mathrm{rl}}: \quad$ Receiver loss coefficient $\left(\mathrm{W} / \mathrm{m}^{2} \mathrm{~K}\right)$

$W_{\mathrm{a}}$ : $\quad$ Aperture width $(\mathrm{m})$

$W_{\mathrm{g}}$ : Solar energy absorbed by glass cover (W)

$W_{\mathrm{r}}$ : $\quad$ Solar energy absorbed by the receiver $(\mathrm{W})$

$X_{\text {exp }}$ : Experimental data value (-)

$X_{\text {model }}$ : Model data value (-)

Y: Parabola parameter.

\section{Greek Symbols}

$\varepsilon_{\mathrm{c}}:$ Emissivity of cover tube (-)

$\varepsilon_{\mathrm{r}}:$ Emissivity of receiver tube (-)

$\eta_{\mathrm{o}}:$ Optical efficiency $(-)$

$\Phi: \quad$ Rim angle $\left({ }^{\circ}\right)$

$\eta$ : Thermal efficiency (-)

$\sigma:$ Stefan Boltzmann constant $\left(\mathrm{W} . \mathrm{m}^{-2} . \mathrm{K}^{-4}\right.$ )

$\theta: \quad$ Angle of incidence $\left(^{\circ}\right)$

$\tau$ : Transmittance of glass cover

$\alpha$ : Absorptance of the receiver

$\gamma$ : Intercept factor

$\rho$ : Reflectance of the mirror.

\section{Additional Points}

Highlights. The highlights of the study are (i) low concentration ratio parabolic trough collector for dehumidification, (ii) thermal model along with experimental validation, (iii) transient analysis of the integrated system in five major cities of Pakistan, (iv) real-time performance investigation on sunny and cloudy days, and (v) dehumidification share of PTC along with solar fraction.

\section{Conflicts of Interest}

The authors declare that they have no conflicts of interest.

\section{References}

[1] S. Bilgen, "Structure and environmental impact of global energy consumption," Renewable and Sustainable Energy Reviews, vol. 38, pp. 890-902, 2014.

[2] A. Fernández-García, E. Zarza, L. Valenzuela, and M. Pérez, "Parabolic-trough solar collectors and their applications," Renewable and Sustainable Energy Reviews, vol. 14, no. 7, pp. 1695-1721, 2010.

[3] İ. H. Yılmaz and M. S. Söylemez, "Thermo-mathematical modeling of parabolic trough collector," Energy Conversion and Management, vol. 88, pp. 768-784, 2014.
[4] C. Tzivanidis, E. Bellos, D. Korres, K. A. Antonopoulos, and G. Mitsopoulos, "Thermal and optical efficiency investigation of a parabolic trough collector," Case Studies in Thermal Engineering, vol. 6, pp. 226-237, 2015.

[5] A. A. Hachicha, I. Rodríguez, R. Capdevila, and A. Oliva, "Heat transfer analysis and numerical simulation of a parabolic trough solar collector," Applied Energy, vol. 111, pp. 581-592, 2013.

[6] R. Silva, M. Pérez, and A. Fernández-Garcia, "Modeling and co-simulation of a parabolic trough solar plant for industrial process heat," Applied Energy, vol. 106, pp. 287-300, 2013.

[7] O. Behar, A. Khellaf, and K. MohAMmedi, "A novel parabolic trough solar collector model - validation with experimental data and comparison to engineering equation solver (EES)," Energy Conversion and Management, vol. 106, pp. 268-281, 2015.

[8] O. García-Valladares and N. Velázquez, "Numerical simulation of parabolic trough solar collector: improvement using counter flow concentric circular heat exchangers," International Journal of Heat and Mass Transfer, vol. 52, no. 3-4, pp. 597-609, 2009.

[9] S. A. Kalogirou, "Parabolic trough collectors for industrial process heat in Cyprus," Energy, vol. 27, no. 9, pp. 813-830, 2002.

[10] M. Ouagued, A. Khellaf, and L. Loukarfi, "Estimation of the temperature, heat gain and heat loss by solar parabolic trough collector under Algerian climate using different thermal oils," Energy Conversion and Management, vol. 75, pp. 191-201, 2013.

[11] A. Valan Arasu and T. Sornakumar, "Design, manufacture and testing of fiberglass reinforced parabola trough for parabolic trough solar collectors," Solar Energy, vol. 81, no. 10, pp. 1273-1279, 2007.

[12] D. Kumar and S. Kumar, "Year-round performance assessment of a solar parabolic trough collector under climatic condition of Bhiwani, India: a case study," Energy Conversion and Management, vol. 106, pp. 224-234, 2015.

[13] M. Biencinto, L. González, and L. Valenzuela, "A quasidynanic simulation model for direct steAM generation in parabolic troughs using TRNSYS," Applied Energy, vol. 161, pp. 133-142, 2016.

[14] F. J. Cabrera, A. Fernández-García, R. M. P. Silva, and M. Pérez-García, "Use of parabolic trough solar collectors for solar refrigeration and air-conditioning applications," Renewable and Sustainable Energy Reviews, vol. 20, pp. 103-118, 2013.

[15] M. A. Sheikh, "Energy and renewable energy scenario of Pakistan," Renewable and Sustainable Energy Reviews, vol. 14, no. 1, pp. 354-363, 2010.

[16] S. Z. Farooqui, "Prospects of renewables penetration in the energy mix of Pakistan," Renewable and Sustainable Energy Reviews, vol. 29, pp. 693-700, 2014.

[17] H. B. Khalil and S. J. H. Zaidi, "Energy crisis and potential of solar energy in Pakistan," Renewable and Sustainable Energy Reviews, vol. 31, pp. 194-201, 2014.

[18] S. A. Kalogirou, Solar Energy Engineering: Processes and Systems, Academic Press, 2013.

[19] R. H. S. Winterton, "Where did the Dittus and Boelter equation come from?," International Journal of Heat and Mass Transfer, vol. 41, no. 4-5, pp. 809-810, 1998.

[20] J. A. Duffie and W. A. Beckman, Solar Engineering of Thermal Processes, vol. 3, Wiley, New York, 2013. 
[21] G. Tiwari and A. Tiwari, "Handbook of Solar Energy: Theory," in Analysis and Applications, Springer, 2016.

[22] S. A. Klein and F. Alvarado, EES: Engineering Equation Solver for the Microsoft Windows Operating System, F-Chart software, 1992.

[23] Laboratory, U.o.W.---M.S.E and S. A. Klein, "TRNSYS, a transient system simulation progrAM," in Solar Energy Laborataory, University of Wisconsin-Madison, 1979.

[24] K. S. Reddy, K. Ravi Kumar, and C. S. Ajay, "Experimental investigation of porous disc enhanced receiver for solar parabolic trough collector," Renewable Energy, vol. 77, pp. 308-319, 2015.

[25] A. Standard, "Methods of testing to determine the thermal performance of solar collectors," ANSK, vol. B198, pp. 1-1977, 1977.

[26] A. Standard, "Methods of testing to determine the thermal performance of solar collectors," in American Society of Heating, pp. 93-77, Refrigeration and Air Conditioning Engineers, Inc., New York, NY, USA, 1977.

[27] M. Chafie, M. F. Ben Aissa, S. Bouadila, M. Balghouthi, A. Farhat, and A. Guizani, "Experimental investigation of parabolic trough collector system under Tunisian climate: design, manufacturing and performance assessment," Applied Thermal Engineering, vol. 101, pp. 273-283, 2016.

[28] D. Hooper, J. Coughlan, and M. Mullen, "Structural equation modelling: guidelines for determining model fit," Art, p. 2, 2008.

[29] G. Coccia, G. Di Nicola, and A. Hidalgo, Parabolic Trough Collector Prototypes for Low-Temperature Process Heat, Swizerland, 2016.

[30] G. Coccia, G. Di Nicola, and M. Sotte, "Design, manufacture, and test of a prototype for a parabolic trough collector for industrial process heat," Renewable Energy, vol. 74, pp. 727-736, 2015. 

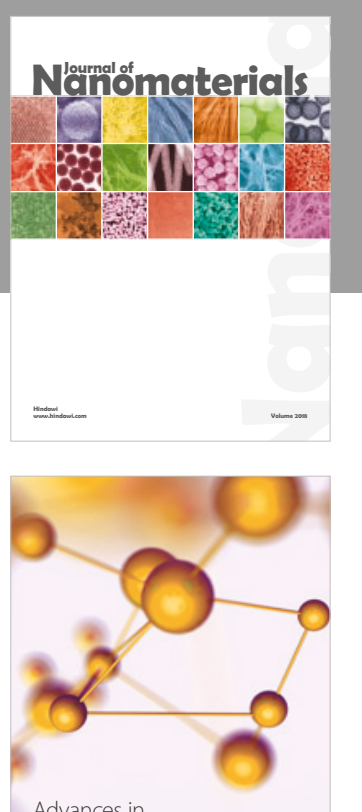

Physical Chemistry
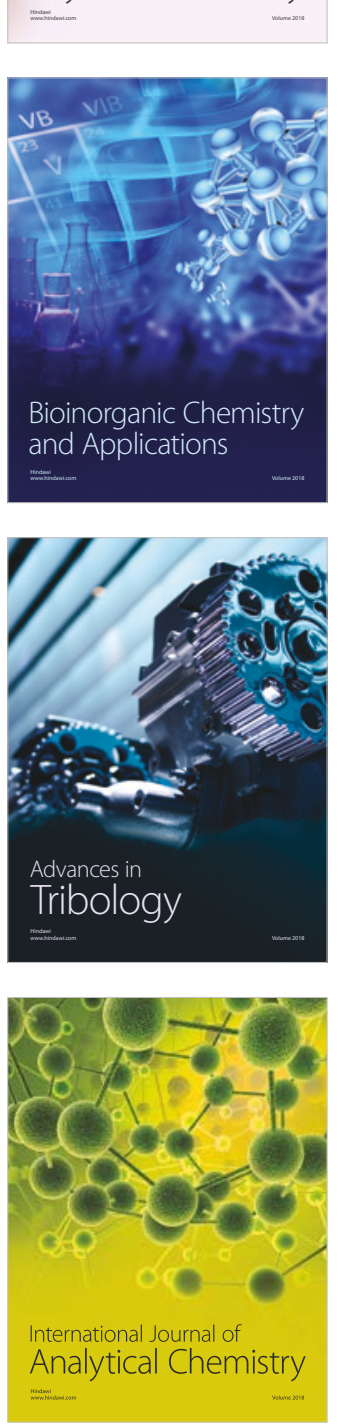

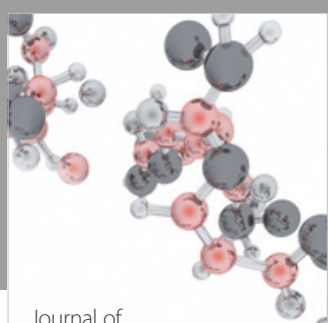

Analytical Methods

in Chemistry

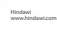

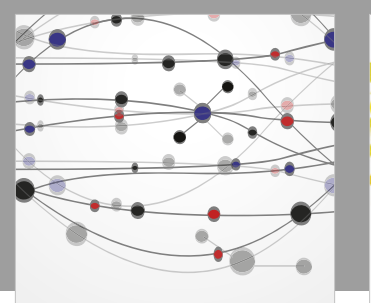

The Scientific World Journal

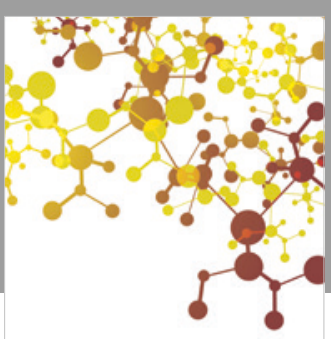

Journal of

Applied Chemistry
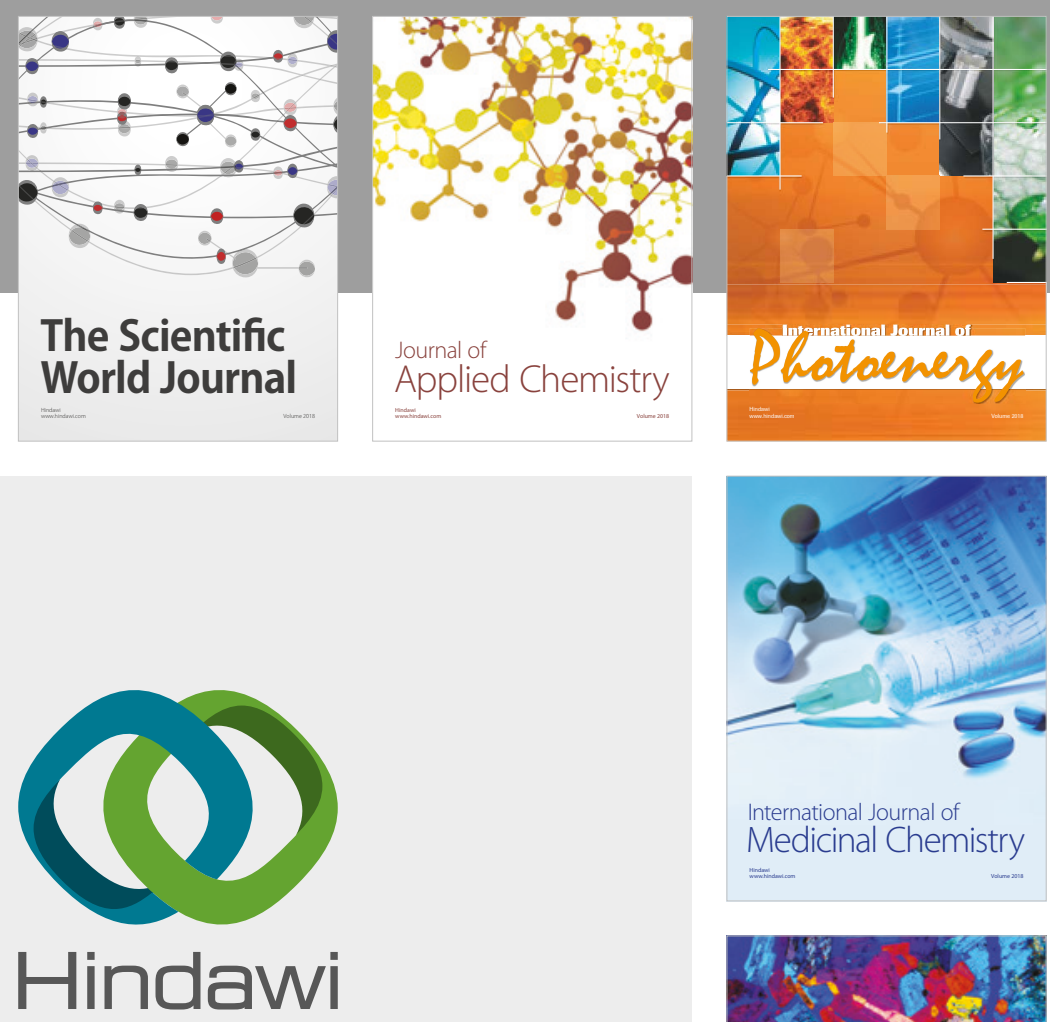

Submit your manuscripts at

www.hindawi.com
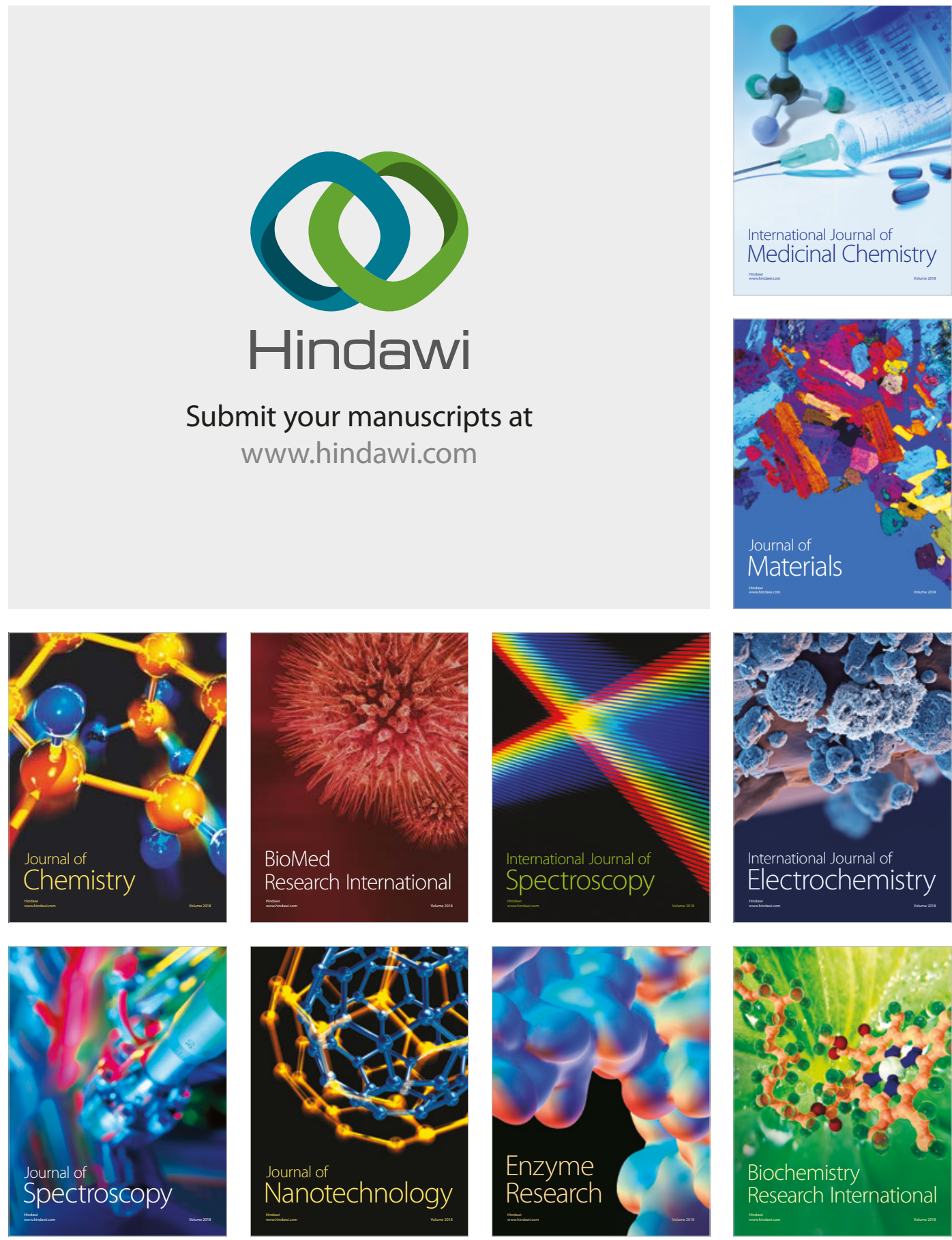
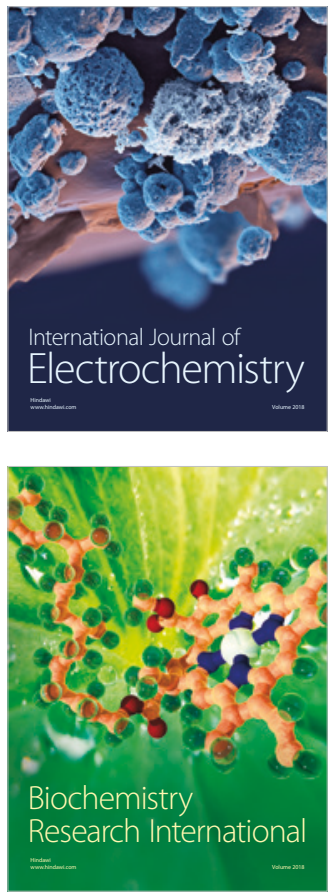